\title{
MEJORAMIENTO GENÉTICO PARA TOLERANCIA A ALTAS TEMPERATURAS Y RESISTENCIA A MOSAICO DORADO EN FRIJOL COMÚN 1
}

\author{
Juan Carlos Rosas ${ }^{2}$, Aracely Castro², James S. Beaver ${ }^{2}$, Carlos A. Pérez ${ }^{2}$, Adrián Morales ${ }^{2}$, Rogelio Lepiz ${ }^{2}$
}

\section{RESUMEN}

Mejoramiento genético para tolerancia a altas temperaturas y resistencia a mosaico dorado en frijol común. Entre 1994-95 se identificaron fuentes de frijol tolerantes a altas temperaturas mediante la evaluación de germoplasma y líneas mejoradas en Choluteca y Nacaome $(\leq 50$ msnm), en la región Sur de Honduras. La tolerancia al calor de los mejores genotipos fue confirmada en Geneva, Nueva York, EE.UU., bajo condiciones de invernadero con temperatura controlada $\left(35 / 27^{\circ} \mathrm{C}\right.$ día/noche). Posteriormente, se realizaron cruzamientos para desarrollar líneas de grano rojo-pequeño tolerantes al calor y resistentes al VMDF y a otros factores limitantes. Las poblaciones segregantes F2-F5 fueron evaluadas por caracteres múltiples incluyendo VMDF, bacteriosis, baja fertilidad, roya, valor agronómico y valor comercial del grano. En 1998, 217 líneas F6 y F7 fueron evaluadas en el distrito de riego Lempa-Acahuapa (20 msnm), región Pacífica de El Salvador, por tolerancia a altas temperaturas y al VMDF. Estas mismas líneas se evaluaron en la localidad de Liberia, en la región Noroeste de Costa Rica, por tolerancia a altas temperaturas; y en El Zamorano, Honduras por resistencia a bacteriosis, mancha angular y roya. Se logró identificar un grupo de líneas que superaron a los testigos comerciales bajo condiciones de altas temperaturas en El Salvador y Costa Rica. Algunas de las líneas seleccionadas presentaron alta resistencia al VMDF en El Salvador, resistencia moderada a mustia en Costa Rica, y excelente comportamiento agronómico y valor comercial del grano.
\end{abstract}

\begin{abstract}
Genetic improvement of the tolerance to high temperature and resistance to bean golden mosaic virus on common beans. In 1994-95, sources of heat tolerance were identified in common beans after screened several germplasm and advanced lines nurseries in Choluteca and Nacaome ( $\leq 50 \mathrm{masl})$, in the southern region of Honduras. The best heat tolerant genotypes were validated under greenhouse controlled conditions $\left(35 / 27^{\circ} \mathrm{C}\right.$ day/night) in Geneva, New York. Afterward, crosses were made to develop small-red bean lines with heat tolerance and resistance to BGMV and other limiting factors. The F2- F5 segregant populations were evaluated for multiple traits including BGMV, common bacterial blight, angular leaf spot, rust, low fertility conditions, and selected for agronomic performance and commercial value. In 1998, 217 F6 and F7 advanced lines were evaluated in the irrigation district Lempa-Acahuapa (20 masl), in the Pacific region of El Salvador for heat tolerance and BGMV. The same nurseries were evaluated in Liberia, in the Northwest region of Costa Rica, for tolerance to high temperatures; and at Zamorano, Honduras for resistance to common bacterial blight, angular leaf spot and rust. A group of lines were identified having superior yield and adaptation than commercial checks, under high temperature conditions in El Salvador and Costa Rica. Some of these lines were also resistant to BGMV in El Salvador, and moderate resistant to web blight in Costa Rica, and they had excellent agronomic performance and good commercial value.
\end{abstract}

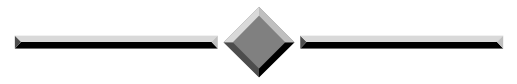

\section{INTRODUCCIÓN}

El frijol común (Phaseolus vulgaris L.) es la fuente principal de proteínas para la mayoría de la población rural y urbana de escasos recursos en Centro América y El Caribe. Es mayormente cultivado por pequeños agri- cultores bajo condiciones de bajos insumos, en áreas marginales o en épocas con limitaciones de lluvias. En general, la tolerancia del frijol común a las altas temperaturas es bastante baja, y la mayoría de las variedades utilizadas por los agricultores están mejor adaptadas a regiones de elevaciones media a alta o a siembras en

\footnotetext{
1 Presentado durante la XLV Reunión Anual del PCCMCA, Guatemala, del 12 al 16 de abril, 1999. Este trabajo fue parcialmente financiado por los Proyectos Bean/Cowpea CRSP (Donación USAID No. DAN-1310-G-SS-6008-00) y PROFRIJOL/COSUDE.

2 J.C. Rosas y A. Castro, Programa de Investigaciones en Frijol (PIF), EAP/Zamorano, Honduras; J.S. Beaver , Universidad de Puerto Rico-Mayagüez; C.A. Pérez, Programa de Granos Básicos, CENTA, El Salvador; A. Morales, Dirección de Investigaciones Agropecuarias, MAG, Costa Rica; R. Lépiz, Programa PROFRIJOL, Guatemala.
} 
épocas con temperaturas moderadas. Se considera que las temperaturas óptimas para el cultivo del frijol son de $18-24^{\circ} \mathrm{C}$, las que caracterizan las regiones tropicales entre los 400-1200 msnm.

La adaptación del frijol a zonas bajas donde predominan temperaturas promedios superiores a $\operatorname{los} 27^{\circ} \mathrm{C}$ es relativamente baja y se manifiesta en incrementos en la tasa de respiración en relación a la tasa fotosíntética. El frijol es particularmente susceptible al estrés del calor durante el desarrollo reproductivo (Weaver et al., 1985). Varios autores sugieren que los efectos de las altas temperaturas nocturnas son más críticos que en el día, lo cual fue confirmado por Dickson y Petzoldt (1991) bajo condiciones controladas con temperaturas nocturnas de $27^{\circ} \mathrm{C}$. Entre los efectos adversos de las temperaturas altas en el cultivo de frijol se encuentran la reducción de la viabilidad del polen, aborto de flores y vainas, reducción del tamaño de la semilla y otros (Halterlein et al., 1980; Dickson y Boetger, 1984; Dickson y Thode, 1985; Weaver et al., 1985; Arndt y Gepts, 1990). Adicionalmente, la fijación de nitrógeno se reduce drásticamente en altas temperaturas porque se afecta la actividad del Rhizobium y el abastecimiento de carbohidratos hacia los nódulos (Hernández et al., 1989).

En la evaluación de poblaciones F2 derivadas de cruzas entre padres tolerantes y susceptibles al calor durante las etapas de formación de botones y llenado de vainas, Arndt y Gepts (1990) estimaron que la tolerancia al calor en frijol es controlada por varios mecanismos genéticos incluyendo la acción de genes mayores, como también efectos aditivos, dominantes y epistáticos. Usando condiciones controladas con temperaturas nocturnas de $27^{\circ} \mathrm{C}$, Dickson y Petzoldt (1991) sugirieron efectos dominantes en la F1 para la formación de vainas en condiciones de altas temperaturas; en las generaciones F2 y retrocruzas recíprocas, encontraron que las estimaciones sobre la herencia de la tolerancia al calor en frijol fueron complejas incluyendo dominancia parcial y epistasis.

El desarrollo de variedades tolerantes al estrés causado por excesivo calor permitiría el cultivo del frijol en algunas regiones bajas tropicales con condiciones más favorables de suelo y lluvias, en donde se podría producir en épocas en que no compitieran con otros cultivos de mayor valor económico, usándose al frijol como cultivo de rotación o en sistemas múltiples intercalados. Además de la tolerancia a altas temperaturas, estas variedades requieren niveles adecuados de resistencia a enfermedades como la bacteriosis común, causada por Xanthomonas campestris pv. phaseoli, y el virus del mosaico dorado del frijol (VMDF) causada por Thanatephorus cucumeris, cuya incidencia y severidad son favorecidas por condiciones de altas temperaturas (Rosas,1998). Asimismo, las temperaturas cálidas favo- recen la proliferación del vector del geminivirus causante del VMDF, la mosca blanca (Bemisia tabaci),y de sus hospederos alternos. En los últimos 15 años, el VMDF se ha constituído en el mayor limitante biótico para la producción de frijol en las zonas bajas de Centro América y el Caribe (Morales, 1994).

En este documento se presentan avances en el mejoramiento de frijol rojo-pequeño para desarrollar variedades tolerantes a altas temperaturas y al VMDF con características favorables para la producción comercial en zonas bajas tropicales de Centro América y El Caribe.

\section{MATERIALES Y MÉTODOS}

El proceso de mejoramiento por tolerancia a altas temperaturas y resistencia al VMDF reportado en este documento comprende las etapas de evaluación de germoplasma, escogencia de progenitores e hibridaciones, desarrollo de líneas mediante la evaluación de poblaciones segregantes, y evaluación de viveros de líneas avanzadas.

Las evaluaciones de germoplasma por tolerancia a altas temperaturas se llevaron a cabo en Choluteca y Nacaome, Honduras (evaluación de germoplasma para la escogencia de progenitores); y en el distrito de riego Lempa-Acahuapa, El Salvador, y en la localidad de Liberia, Costa Rica (evaluaciones de viveros de líneas avanzadas). Las evaluaciones por resistencia al VMDF se hicieron en Comayagua, Honduras; Cuyuta, Guatemala (poblaciones segregantes); y en Lempa-Acahuapa, El Salvador (viveros de líneas avanzadas). También se efectuaron evaluaciones por bacteriosis común, mancha angular y roya, en las poblaciones segregantes y en los viveros de líneas avanzadas en el Zamorano, Honduras.

\section{Evaluaciones de germoplasma}

Durante 1994-95 se realizaron evaluaciones de germoplasma en dos localidades de la región costera del sur de Honduras, Choluteca y Nacaome, y una de la costa norte, La Ceiba. En Choluteca se condujeron evaluaciones en la localidad de Pavana, ubicada a $13^{\circ} 15^{\text {, }}$ LN y $87^{\circ} 22^{\prime} \mathrm{LO}$, a una elevación de $45 \mathrm{msnm}$. La temperatura promedio anual en esa localidad es superior a $27^{\circ} \mathrm{C}$, con temperaturas máximas de $45^{\circ} \mathrm{C}$. La precipitación promedio anual es de 1,724 $\mathrm{mm}$. La localidad de Nacaome se encuentra en el departamento de Valle, a $13^{\circ} 31^{\prime} \mathrm{LN}$ y $87^{\circ} 29^{\prime} \mathrm{LO}$ y una altitud de $40 \mathrm{msnm}$, con temperatura promedio anual superior a $27{ }^{\circ} \mathrm{C}$, con temperaturas máximas de $42{ }^{\circ} \mathrm{C}$, y presentó una precipitación promedio anual de $1,300 \mathrm{~mm}$. La Ceiba se encuentra en el departamento de Atlántida, en la costa norte de Honduras, a $15^{\circ} 47^{\prime} \mathrm{LN}$ y $86^{\circ} 46^{\prime} \mathrm{LO}$ y una altitud de $18 \mathrm{msnm}$, con una temperatura promedio anual 
superior a los $27^{\circ} \mathrm{C}$ y una precipitación de 2,600 msnm. Durante el período de floración y desarrollo de las vainas, en las evaluaciones de germoplasma se alcanzaron temperaturas mínimas promedios de 28,28 y $23{ }^{\circ} \mathrm{C}$ y temperaturas máximas promedios de 39,37 y $35^{\circ} \mathrm{C}$ en las localidades de Pavana, Nacaome y La Ceiba, respectivamente. Adicionalmente, en 1995 se evaluaron los genotipos identificados como tolerantes a nivel de campo, bajo condiciones de invernadero $\left(38 / 27^{\circ} \mathrm{C}\right.$ dia/noche) en Geneva, Nueva York, con la colaboración del Dr. Mike Dickson. En total, durante 1994-95 se evaluaron 11 viveros incluyendo 320 genotipos entre accessiones de germoplasma y líneas mejoradas. La relación de los viveros, épocas, años y localidades de evaluación se indican en el Cuadro 1.

\section{Selección de progenitores e hibridaciones}

Los genotipos identificados por su mayor tolerancia al calor ingresaron al programa de hibridaciones para el mejoramiento por resistencia múltiple a factores bióticos y abióticos desarrollado por el PIF/Zamorano, en colaboración con los proyectos del Bean/Cowpea CRSP y PROFRIJOL. El objetivo principal de este programa de mejoramiento era desarrollar líneas mejoradas que recombinaran la tolerancia a altas temperaturas con resistencia a enfermedades predominantes en zonas bajas tropicales donde el potencial de tolerancia al calor pudiera ser explotado. Entre las enfermedades principales bajo estas condiciones se encuentran el VMDF, la bacteriosis común y la mustia hilachosa (en zonas húmedas bajas). Se decidió dar más énfasis a la recombinación de la tolerancia al calor con la resistencia al
VMDF; sin embargo, a lo largo del proceso de mejoramiento se enfatizó aunque en menor grado, en la resistencia a la bacteriosis común, mancha angular y roya. La recombinación de estos caracteres mediante hibridación y selección, se hizo con base en un ideotipo de frijol de hábito arbustivo-indeterminado, grano-rojo pequeño brillante, con madurez temprana-intermedia y buen comportamiento agronómico. Para ello se utilizó como progenitores en los cruzamientos un número significativo de líneas avanzadas rojo-pequeñas que mostraron tolerancia al calor y que a su vez tenían un nivel de resistencia moderada-alta al VMDF.

Se desarrollaron dos tipos de recombinaciones (Cuadro 2). El primer grupo de hibridaciones se realizó mediante cruza simple Elite x Elite, desarrollándose las poblaciones identificadas como EAP y PTC. Los progenitores élites fueron líneas de grano rojo-pequeño, con resistencia moderada-alta al VMDF, que anteriormente habían sido incluídas en viveros avanzados donde mostraron buena adaptación y potencial de rendimiento, bajo condiciones normales de producción. Varias de estas líneas élites resultaron ser también tolerantes a altas temperaturas (p.e. MD 30-75, 9021-14, 9356-26, etc). Por lo menos uno de los padres de las cruzas simples Elite x Elite para el desarrollo de estas poblaciones, fue escogido por su tolerancia a altas temperaturas.

El segundo grupo de hibridaciones se hizo mediante cruzas múltiples, usándose progenitores de diversas fuentes mesoamericanas y andinas de resistencia al VMDF, bacteriosis común, mancha angular, mustia hilachosa y otros factores limitantes. Estas fuentes de resistencia fueron recombinadas mediante hibridaciones

Cuadro 1. Relación de viveros de germoplasma y líneas avanzadas evaluados para la identificación de fuentes tolerantes a altas temperaturas en las localidades de Choluteca, Nacaome y La Ceiba. Honduras, 1994-95.

\begin{tabular}{lclc}
\hline \multicolumn{1}{c}{ Viveros } & $\begin{array}{c}\mathbf{N}^{\circ} \\
\text { Genotipos }\end{array}$ & Localidad & Año / Epoca $^{2}$ \\
\hline 1. Germoplasma hondureño $(\leq 400 \mathrm{msnm})$ & 56 & Choluteca & $94 \mathrm{X}$ \\
2. Líneas avanzadas (UPR, SRCO, otros) & 1 & Choluteca & $94 \mathrm{X}$ \\
3. VIFURE (CIAT) & 120 & Choluteca & $94 \mathrm{X}$ \\
4. Líneas avanzadas (RELAF-94) & 10 & La Ceiba & $94 \mathrm{~B}$ \\
5. VINAR & 16 & La Ceiba & $94 \mathrm{~B}$ \\
6. Selecciones ATS-94 & 64 & La Ceiba & $94 \mathrm{~B}$ \\
& 64 & Nacaome & $94 \mathrm{~B}$ \\
7. Selecciones ATS-95-124La Ceiba95X & & & \\
& 24 & Nacaome & $95 \mathrm{X}$ \\
8. Líneas avanzadas (RELAF-95) & 10 & La Ceiba & $95 \mathrm{X}$ \\
9. Selecciones ATS-95-2 & 25 & Nacaome & $95 \mathrm{X}$ \\
10. LITOLAT 1 & 10 & Nacaome & $95 \mathrm{~B}$ \\
11. LITOLAT 2 & 15 & Geneva, NY & $95 \mathrm{~B}$ \\
\hline
\end{tabular}

${ }^{1}$ Incluye germoplasma y líneas avanzadas de los programas de frijol del CIAT, UPR y Zamorano.

2 Épocas: X (enero-abril, verano bajo riego); B(septiembre-diciembre, postrera). 
Cuadro 2. Relación de las poblaciones y los pedigrís de las cruzas de donde se seleccionaron las líneas avanzadas F6 y F7 evaluadas por tolerancia a altas temperaturas, mosaico dorado y otros factores limitantes ${ }^{1}$.

\begin{tabular}{llll}
\hline Población & \multicolumn{1}{c}{ Pedigrí } & \multicolumn{1}{c}{ Población } & \multicolumn{1}{c}{ Pedigrí ${ }^{2}$} \\
\multicolumn{2}{c}{ Líneas F6 } & Líneas F7 \\
EAP 9501 & Yeguare/MD30-37 & PRF 9651 & EAP9501/RS1 \\
EAP 9502 & Don Victor/MD30-75 & PRF 9652 & EAP9502/RS2 \\
EAP 9503 & MD23-24/MD30-37 & PRF 9653 & EAP9503/RS3 \\
EAP 9504 & $9021-14 /$ MD30-37 & PRF 9654 & EAP9504/RS4 \\
EAP 9505 & 9177-214-1/MD30-75 & PRF 9655 & EAP9505/RS5 \\
EAP 9506 & $9356-26 / M D 30-75$ & PRF 9657 & EAP9501/EAP9502//AL12 \\
PTC 9551 & $9021-14 /$ MD23-24 & PRF 9659 & EAP9504/EAP9506//BG12/WB12 \\
PTC 9552 & $9021-14 / 9356-26$ & PRF 9660y & EAP9510//BG12/WB12 \\
PTC 9553 & $9021-14 / 9438-129$ & & \\
PTC 9554 & MD23-24/9356-26 & & \\
PTC 9555 & MD23-24/94-38-129 & & \\
PTC 9556 & 9356-26/9438-129 & & \\
RS3 & (A429/K2)(V8025/XR16492//APN83/CNC) & \\
RS4 & (Red Mex 36/ARA14)(BAT477/Wilk2//BARC-RR7/Negro150) & \\
\hline
\end{tabular}

\footnotetext{
1 Ver mayores detalles sobre cruzas en Cuadro 4.

2 Pedigrís: RS1= BAT477/Wilk2///A429/K2//APN83/CNC; RS2=V 8025/XR16492///RedMex36/ARA14//BARCRR7/Negro150; RS5=APN83/CNC///V8025/XR16492//A429/K2; AL12=ARA14/K2//RAB485/G5686; BG12= A429/PintoUI114//GN31/RedMex36; WB12=MUS138/BAT450//MUS132/HT1683-6; EAP9510 = MD30-75/ DICTA 105
}

múltiples, con el fin de desarrollar las cruzas múltiples donantes (progenitores masculinos) que fueron recombinadas con cruzas simples o dobles de líneas élites de grano rojo-pequeño (progenitores femeninos) para desarrollar las poblaciones identificadas como RS y PRF. Para las fases de cruzamiento y selección en generaciones segregantes del grupo de poblaciones PRF derivadas de cruzamientos múltiples, se siguió el método de selección de gametos (Singh, 1994).

El Cuadro 2 muestra las poblaciones (y sus pedigrís) generadas para el programa de mejoramiento para tolerancia al calor, VMDF y otros factores limitantes para regiones bajas tropicales de Centro América. En este cuadro sólo se incluyen las poblaciones de las líneas avanzadas (F6 y F7) que resultaron de la selección por varios factores limitantes, en las generaciones segregantes F2 a F6 durante 1997-98. Las líneas avanzadas F6 y F7 fueron evaluadas en la postrera de 1998 por tolerancia al calor y resistencia al VMDF en El Salvador y Costa Rica.

\section{Evaluación de líneas avanzadas}

Como se mencionó, las líneas avanzadas F6 y F7 de las poblaciones indicadas en el Cuadro 2, fueron evaluadas por tolerancia a altas temperaturas y resistencia al VMDF en Lempa-Acahuapa, El Salvador, y por tolerancia al calor en Liberia, Costa Rica. Adicionalmente, un juego de estos viveros fue evaluado por bac- teriosis común y mancha angular en camas de infección, y roya y valor agronómico a nivel de campo, en Zamorano, Honduras.

La localidad de Lempa-Acahuapa está localizada en la región del litoral Pacífico de El Salvador, $13^{\circ} 36^{\prime}$ $\mathrm{LN}$ y $88^{\circ} 38^{\prime} \mathrm{LO}$, a $20 \mathrm{msnm}$, con temperaturas promedio de $29,5^{\circ} \mathrm{C}$. Adicionalmente, en esta zona la incidencia del VMDF es muy alta. La localidad de Liberia, está localizada en la región Noroeste en el Pacífico de Costa Rica; las temperaturas promedio durante la conducción de los viveros en Liberia fue de $26-27^{\circ} \mathrm{C}$, y se presentó incidencia de mustia hilachosa. La localidad de Zamorano, ubicada en la región centro-oriental de Honduras, se utilizó para las evaluaciones a otros factores como complemento a las de tolerancia a altas temperaturas realizadas en El Salvador y Costa Rica.

Los viveros de líneas avanzadas (LINAF) estuvieron constituidos por 114 líneas F6 provenientes de 14 poblaciones y 103 líneas F7 de ocho poblaciones. Las parcelas de evaluación de las líneas avanzadas fueron sembradas con 30 semillas en un surco sencillo por línea. Se utilizaron variedades comerciales y mejoradas como testigos cada 10-20 líneas. Los criterios de selección para tolerancia al calor fueron basados en rendimiento per se y valor agronómico. Las evaluaciones de las reacciones al VMDF (Lempa-Acahuapa), mustia hilachosa (Liberia), y bacteriosis, mancha angular y roya 
(Zamorano), se hicieron utilizando la escala de severidad del CIAT (1987). Adicionalmente, en Costa Rica y en Honduras se realizaron evaluaciones del valor comercial del grano usando una escala 1-9 para grano rojo-pequeño brillante $(1=$ excelente, similar a las mejores variedades criollas; y $9=$ muy pobre). Como referencia, la escala usada en Honduras ubica a los tipos Chile o Chingo (similares a Rojo de Seda) en el grado 1; Desarrural y Catrachita en el grado 3; Tío Canela-75 en el grado 5; y Dorado en el grado 7.

\section{RESULTADOS Y DISCUSIÓN}

\section{Evaluación de germoplasma}

Más del 90\% del germoplasma y líneas mejoradas evaluadas en Honduras mostraron una alta sensibilidad al estrés de altas temperaturas. El estrés se manifestó mayormente en aborto de flores y de vainas pequeñas; como consecuencia, el número de vainas por planta fue muy reducido o nulo. Las escazas vainas formadas de los genotipos sensibles eran mayormente vanas o con un número muy bajo de granos. Los granos eran de menor tamaño o la mayoría no llegaban a maduración normal, siendo arrugados o deformes. La mayoría de los genotipos tuvieron un crecimiento vegetativo aceptable, observándose que los efectos negativos se presentaron en el desarrollo reproductivo. La ampliación de la duración del período de floración sin formación de vainas o de vainas vanas, fue una característica generalizada de los genotipos sensibles.

Se identificó un grupo aceptable de genotipos tolerantes al calor dentro de la clase comercial rojo-pequeño (raza mesoamericana), incluyendo accesiones de germoplasma recolectadas en localidades por debajo de los 400 msnm y líneas mejoradas. En el Cuadro 3 se observa los datos de rendimiento de los genotipos que mostraron tolerancia al calor y la de los testigos comerciales en los viveros evaluados en Honduras. Entre las accesiones tolerantes del germoplasma recolectado en Honduras, en localidades ubicadas en zonas relativamente bajas de las regiones productoras de frijol $(<400$ msnm), se encuentra la accesion F0155 que produjo en

Cuadro 3. Resumen de los rendimientos en las evaluaciones de viveros para la identificación de fuentes de tolerancia a altas temperaturas en las localidades de Choluteca y Nacaome, Honduras, y Geneva, Nueva York. 1994-95.

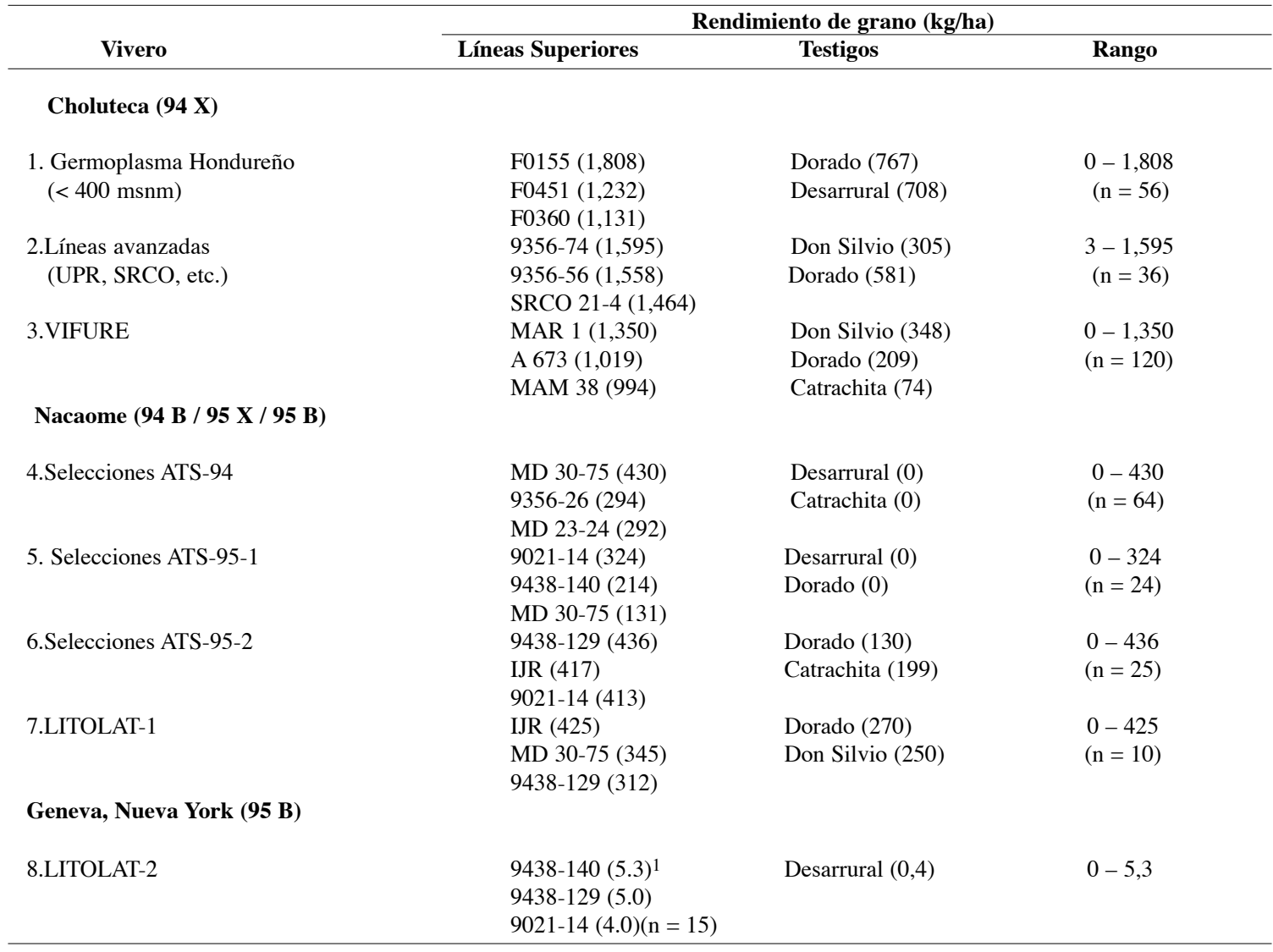

\footnotetext{
${ }^{1} \mathrm{~N}^{\circ}$ de vainas por planta (condiciones controladas, Universidad de Cornell).
} 
Pavana, Choluteca, en el verano de 1994, más del doble $(1,808 \mathrm{~kg} / \mathrm{ha})$ que las variedades comerciales Dorado (767 kg/ha), Don Silvio (632 kg/ha) y Desarrural (708 $\mathrm{kg} / \mathrm{ha}$ ), y el cuadruple que las variedades criollas Cuarenteño $(388 \mathrm{~kg} / \mathrm{ha})$ y Chingo $(239 \mathrm{~kg} / \mathrm{ha})$. En un vivero de líneas avanzadas (UPR, SRCO, etc) de grano rojopequeño, conducido en esa misma época, sobresalieron las líneas UPR 9356-74 y UPR 9356-26 y SRCO 21-4 con rendimientos aproximados a $1500 \mathrm{~kg} / \mathrm{ha}$, muy superior a los testigos Don Silvio (305 kg/ha) y Dorado (581 $\mathrm{kg} / \mathrm{ha}$ ). En la evaluación del VIFURE (Vivero de Fuentes de Resistencia del CIAT), constituido por 120 accesiones, se destacaron MAR $1(1,350 \mathrm{~kg} / \mathrm{ha})$ y A673 $(1,019 \mathrm{~kg} / \mathrm{ha})$, superando significativamente a los testigos Don Silvio (348 kg/ha), Dorado (209 kg/ha) y Catrachita $(74 \mathrm{~kg} / \mathrm{ha}$ ); en este vivero, 73 accesiones (aprox. $20 \%$ ) tuvieron un rendimiento inferior a $100 \mathrm{~kg} / \mathrm{ha}$ y más de la mitad de estos genotipos no formaron granos.

En las evaluaciones del ensayo Selecciones ATS94 en Nacaome, Valle, en la postrera (octubrediciembre) de 1994, sólo 11 de los 64 genotipos incluídos lograron formar vainas llenas. Debido a las temperaturas más altas en Nacaome que en Choluteca, aún los rendimientos de los genotipos superiores fue relativamente bajo, siendo la línea MD 30-75 la mejor con $430 \mathrm{~kg} / \mathrm{ha}$, seguida de las líneas UPR 9356-26 y MD 23-24 con casi $300 \mathrm{~kg} / \mathrm{ha}$; en este ensayo los testigos Desarrural y Catrachita no produjeron nada. Adicionalmente a las temperaturas extremas, Nacaome presenta una humedad relativa muy baja, por lo que el estrés es mucho mayor que en la localidad de Pavana, Choluteca. En otros dos ensayos (Selecciones ATS 951 y ATS 95-2) conducidos en Nacaome en el verano de 1995 (febrero-abril), se evaluaron 49 genotipos incluyendo líneas avanzadas, en su mayoría de los programas de mejoramiento de la Universidad de Puerto Rico y de Zamorano. Los genotipos que destacaron por rendimiento de grano fueron las líneas mejoradas de grano rojo-pequeño EAP 9021-14, UPR 9438-129, UPR 9438-140, MD 30-75 (277- $347 \mathrm{~kg} / \mathrm{ha})$, y la variedad Indeterminada Jamaica Red (IJR, $421 \mathrm{~kg} / \mathrm{ha}$ ) de grano rojo-arriñonado; esta última fue una de las pocas accesiones andinas en las que se observó tolerancia al calor. En el ensayo LITOLAT 1 destacaron nuevamente IJR, MD 30-75 y UPR 9438-129, sobre los testigos Dorado y Don Silvio. En la mayoría de estos ensayos hubo genotipos con muy pobre producción $(<100 \mathrm{~kg} / \mathrm{ha})$ o sin rendimiento de grano.

En el verano de 1995 también se observó el extremo estrés causado por las altas temperaturas y baja humedad relativa en la localidad de Nacaome. Pese a que los rendimientos de los mejores genotipos fueron relativamente bajos, las diferencias observadas en relación a los genotipos sensibles y a los testigos comerciales fueron notorias; en este sentido, el hecho de llegar a formar vainas llenas y producir granos es una indicación de tolerancia a las condiciones extremas de altas temperaturas predominantes. Más aún, la tolerancia a altas temperaturas de las líneas identificadas en Nacaome, fue confirmada bajo condiciones controladas usando altas temperaturas durante el día/noche en la Universidad de Cornell en Geneva, Nueva York.

Las evaluaciones llevadas a cabo en las épocas de verano (febrero-abril) y postrera (octubre-diciembre) de 1994 y 1995 en la localidad de La Ceiba no resultaron muy efectivas, debido a que las temperaturas mínimas promedio registradas en estas épocas fue de sólo $23{ }^{\circ} \mathrm{C}$, la cual no causa suficiente estrés. Sin embargo, durante la época de primera (junio-agosto) se presentan temperaturas nocturnas más altas, por lo que sería la mejor época para evaluaciones de adaptación al calor en esta localidad. A pesar de esto, las evaluaciones realizadas en esta localidad en 1994 y 1995 permitieron identificar líneas avanzadas con rendimiento superior y mayor resistencia a enfermedades que el testigo local Arbolito; estos resultados no se incluyen en este documento por no estar relacionados a tolerancia al calor.

\section{Selección de progenitores e hibridaciones}

La escogencia de padres se efectuó tratando de incluir en el programa de cruzamientos dos grupos de progenitores: el primero incluyó las mejores líneas tolerantes al calor con tipo de grano rojo-pequeño y otras características agronómicas deseables, calificadas como líneas élites dentro de esta clase comercial por su potencial de rendimiento, resistencia a algunas enfermedades y calidad de grano. Con estas líneas élites se desarrollaron cruzas simples Elite x Elite (poblaciones EAP y PTC). El segundo grupo de progenitores incluyó las mejores fuentes de resistencia a varios factores limitantes, provenientes de los reservorios mesoamericano y andino, utilizados para el desarrollo de las cruzas múltiples donantes. Las poblaciones RS se derivaron de una cruza Simple x Doble (6 progenitores). Las poblaciones PRF se derivaron de recombinaciones entre cruzas simples o dobles élites (progenitores femeninos) por cruzas múltiples donantes del segundo grupo (progenitores masculinos), resultando en hibridaciones múltiples que incluyeron de 8 a 12 progenitores. Mayores detalles de los esquemas usados en la fase de hibridación se observa en el Cuadro 4A. Como se puede apreciar todas las hibridaciones realizadas (cruzas simples élites o utilizando progenitores múltiples), estuvieron dirigidas a recombinar tolerancia a altas temperaturas con resistencia al VMDF y otros factores adicionales, tratando de obtener estas recombinaciones 
en un ideotipo comercial de grano rojo-pequeño con excelente valor agronómico, madurez temprana-intermedia, y buen potencial de rendimiento.

Afortunadamente, en las evaluaciones por tolerancia al calor se pudieron identificar entre las líneas mejoradas varios genotipos tolerantes, que ádemas del tipo comercial rojo-pequeño, poseían un nivel aceptable de resistencia al VMDF y a la bacteriosis común, buena arquitectura y madurez intermedia. Varias de estas líneas provenían de cruzamientos entre genotipos identificados por su resistencia al VMDF y bacteriosis común en evaluaciones de viveros y ensayos regionales. Entre las líneas tolerantes al calor de grano rojo-pequeño se encontraban EAP 9021-14, MD 30-75, UPR 9438-129 y UPR 9438-140, las cuales ingresaron al programa de cruzas como progenitores élites junto a otros genotipos como las variedades Yeguare y Don Víctor, resistentes a bacteriosis común, antracnosis y roya, adoptadas por algunos agricultores de la región centro-oriental de Honduras; y la línea MD 23-24 actualmente en proceso de validación en algunas regiones de Costa Rica.

\section{Evaluación de poblaciones segregantes}

Las poblaciones desarrolladas fueron sometidas a un proceso de evaluación y selección a partir de la F2. El grupo de poblaciones identificadas como PRF siguieron el método de selección de gametos (Singh, 1994) y fueron manejadas como familias a partir de la F2, iniciándose la selección con 624 familias provenientes de nueve poblaciones. En el grupo de poblaciones identificadas como EAP, PTC y RS se conformaron familias F3 a partir de la selección de plantas individuales F2 (resultantes de la evaluación de 21,659 plantas F2 de 20 poblaciones). De la F3 a la F5, ambos grupos de poblaciones se manejaron de manera similar seleccionando las mejores familias y las mejores plantas/familia seleccionada en las generaciones F3 y F4. En la F5 se cosecharon las mejores plantas de las mejores familias haciendo compuestos de semillas F6, obteniéndose suficiente cantidad de semilla para su evaluación en otras localidades.

Además de los esquemas de cruzamiento, en el Cuadro 4B se delínea el proceso de selección seguido con las poblaciones desarrolladas para este programa.

Cuadro 4. Detalles de las fases de hibridación y evaluación de poblaciones segregantes para el desarrollo de líneas avanzadas con tolerancia a altas temperaturas, mosaico dorado y otros factores limitantes.

\begin{tabular}{clll}
\hline A. Hibridación & & & \\
\hline Poblaciones & Recombinación & Tipo de Cruza & Factores $^{\mathbf{2}}$ \\
\hline EAP 9501-06 & Elite x Elite & Simple & AT, MD, VA, VC, BC, AN \\
PTC 9551-56 & Elite x Elite & Simple & AT, MD, VA, VC \\
RS 3, 4 y 6 & Simple x Doble & Múltiple 6P & MD, VC, AN, BC, RY, AP, SE \\
PRF 9651-55 & Simple Elite x Mult. 6P & Múltiple 8P & Todos los anteriores + AT \\
PRF 9657 & Doble Elite x Doble MA & Múltiple 8P & AT, MD, VC, VA, BC, MA \\
PRF 9659-60 & Doble Elite x & Múltiple 12P & Todos los anteriores + MD y MH \\
& (Doble MA x Doble MH) & & \\
\hline
\end{tabular}

B. Evaluación de poblaciones segregantes

$\begin{array}{lll}\text { Generación } & \text { Fanejo y Selección } \\ \text { F1 } & \text { Plantas Individuales } & \text { MD, VA, VC, } \\ \text { Fiveros Regionales } & \text { Líneas F6 } & \text { Bes, MA, BF }\end{array}$

1 Elite (grano rojo-pequeño brillante, potencial de adaptación y rendimiento, buena arquitectura y madurez); 6P, 8P y 12P (número de progenitores en las cruzas múltiples).

2 AT (altas temperaturas); MD (mosaico dorado); VA (valor agronómico); VC (valor comercial); BC (bacteriosis); AN (antracnosis); RY (roya); AP (picudo de la vaina); SE (sequía); MA (mancha angular); MH (mustia hilachosa); BF (baja fertilidad). 
Los criterios en el proceso de selección en las poblaciones segregantes incluyeron arquitectura de planta, madurez temprana-intermedia, valor agronómico, resistencia a enfermedades incluyendo bacteriosis común, mancha angular y roya (alta incidencia), y mustia hilachosa y VMDF (incidencia intermedia) que se presentaron en Zamorano en forma natural y variable durante las épocas de evaluación en 1997-98. En algunas ocasiones se hicieron inoculaciones artificiales para la bacteriosis común (aspersión de inóculo con bomba de motor) y mancha angular (distribución de rastrojo del cultivo anterior). Se realizaron dos evaluaciones de VMDF en las poblaciones segregantes; una en Comayagua, Honduras (familias F3) y una en Cuyuta, Guatemala (familias F5). Estas evaluaciones de VMDF fueron utilizadas en el avance hacia las siguientes generaciones de la semilla manejada en Zamorano. Por otro lado, se realizaron selecciones por rendimiento y valor comercial de grano, siendo más estrictos en las generaciones avanzadas.

\section{Evaluación de viveros de líneas avanzadas}

Dos viveros de líneas avanzadas F6 (114 líneas EAP, PTC y RS) y F7 (103 líneas PRF) fueron distribuídos a los programas nacionales de El Salvador, Costa Rica, Cuba, Guatemala y Panamá, para su evaluación bajo condiciones de altas temperaturas y VMDF, principalmente, $\mathrm{y}$ a otros factores predominantes en esas regiones. Adicionalmente, en Zamorano se realizaron evaluaciones para bacteriosis común y mancha angular en camas de infeccción; roya y valor agronómico en el campo; y valor comercial del grano en la etapa de postcosecha.

En el Cuadro 5 se presentan los resultados de las evaluaciones en Lempa-Acahuapa, El Salvador. Las altas temperaturas y la alta incidencia del VMDF permitieron identificar un grupo de líneas que recombinan resistencia a ambos factores, y que adicionalmente presentan buenas características agronómicas y de calidad de grano. La tolerancia a altas temperaturas se estimó con base en el valor agronómico (vigor reproductivo, hábito de crecimiento, resistencia al VMDF y a

Cuadro 5. Rendimiento de grano, valor agronómico y reacción a mosaico dorado en Lempa-Acahuapa, El Salvador; y valor comercial, reacción a bacteriosis, mancha angular y roya en Zamorano, Honduras, de las líneas tolerantes a altas temperaturas seleccionadas en el distrito de riego Lempa-Acahuapa. 1998 ${ }^{1}$.

\begin{tabular}{|c|c|c|c|c|c|c|c|}
\hline \multirow[b]{2}{*}{ Línea } & \multicolumn{3}{|c|}{ Lempa-Acahuapa } & \multicolumn{4}{|c|}{ Zamorano } \\
\hline & RG & VA & MD & vC & BC & MA & $\mathbf{R Y}$ \\
\hline \multicolumn{8}{|l|}{ Vivero F6 } \\
\hline EAP 9501-58 & 7,0 & 4 & 1 & 5 & 3,3 & 7 & 3 \\
\hline EAP 9503-14 & 5,8 & 4 & 1 & 5 & 3,3 & 6 & 5 \\
\hline EAP 9503-45B & 13,4 & 6 & 1 & 6 & 2,5 & 5 & 7 \\
\hline EAP 9503-46 & 12,3 & 5 & 1 & 3 & 6,0 & 6 & 5 \\
\hline EAP 9504-3B & 5,6 & 3 & 1 & 4 & 5,0 & 7 & 3 \\
\hline EAP 9504-21A & 6,8 & 3 & 2 & 3 & 4,7 & 5 & 9 \\
\hline EAP 9504-24A & 5,9 & 3 & 1 & 4 & 3,3 & 7 & 9 \\
\hline EAP 9504-24B & 9,3 & 5 & 1 & 5 & 3,3 & 8 & 9 \\
\hline EAP 9506-30 & 10,0 & 6 & 1 & 4 & 3,5 & 7 & 7 \\
\hline PTC 9551-8B & 5,6 & 4 & 1 & 4 & 5,3 & 7 & 7 \\
\hline \multicolumn{8}{|l|}{ Vivero F7 } \\
\hline PRF 9651-71-3A & 5,8 & 5 & 3 & 3 & 2,3 & 7 & 7 \\
\hline PRF 9652-37-1 & 9,7 & 6 & 2 & 6 & 4,7 & 7 & 9 \\
\hline PRF 9653-4-3 & 7,5 & 4 & 3 & 5 & 6,5 & 7 & 9 \\
\hline PRF 9653-16B-2A & 8,0 & 6 & 1 & 6 & 4,0 & 7 & 5 \\
\hline PRF 9655-44A-4 & 9,2 & 4 & 2 & 4 & 3,3 & 8 & 5 \\
\hline \multicolumn{8}{|l|}{ Testigos } \\
\hline DOR 58 & N/D & 6,2 & 6 & -- & -- & -- & -- \\
\hline Rojo de Seda & 0 & 9,0 & 9 & - & - & -- & -- \\
\hline Catrachita & -- & 8,0 & 8 & 3 & 8,0 & 8,5 & 9 \\
\hline Dorado & -- & - & - & 7 & 6,0 & 7,0 & 7 \\
\hline
\end{tabular}

1 RG (rendimiento de grano en g/planta, valores de una sola repetición); VA (valor agronómico, incluyendo vigor reproductivo, arquitectura de planta, resistencia a mosaico dorado y a pudriciones radicales); MD (mosaico dorado); VC (valor comercial); BC (bacteriosis); MA (mancha angular); RY (roya). 
pudriciones radicales) y rendimiento por planta. También se hicieron evaluaciones de la severidad del VMDF. Se identificaron líneas con mayor adaptación a altas temperaturas (valor agronómico $\leq 5$, en la escala 1a 9) que el mejor testigo (DOR 582); teniendo algunas de estas líneas la ventaja adicional de ser más resistentes al VMDF que esta línea. El otro testigo, la variedad criolla Rojo de Seda, fue altamente afectado por ambos factores, observándose que bajo las condiciones del ensayo su producción fue casi nula.

En la localidad de Liberia, Costa Rica, se identificó un grupo de líneas tolerantes al calor con rendimiento de casi el doble que el testigo comercial, la variedad de grano negro Huasteco, así como excelente comportamiento agronómico y buen valor comercial del grano (Cuadro 6). En estos viveros se incluyó la línea MD 2324 , que está en proceso de validación en algunas regiones de Costa Rica, siendo esta superior a Huasteco, aunque algunas de las líneas tolerantes a altas temperaturas se comportaron mejor que ella.
En los Cuadros 5 y 6 se incluyen también los resultados de evaluaciones realizadas en Zamorano por bacteriosis común (inoculación artificial con agujas mútiples) y mancha angular (uso de rastrojo de lotes infestados) en camas de infección; y de roya y valor comercial de parcelas en el campo, con el propósito de ampliar los resultados de las líneas que se destacaron por su tolerancia a altas temperaturas en El Salvador (incluyendo resistencia al VMDF) y Costa Rica. Como se observa, varias de las líneas identificadas como tolerantes al calor presentan un buen nivel de resistencia a bacteriosis común con respecto al testigo susceptible Catrachita. En la reacción a mancha angular se observan niveles intermedios en algunas de estas líneas, mientras el testigo tuvo reacción susceptible. Entre las líneas seleccionadas en El Salvador que recombinan tolerancia al calor y resistencia al VMDF, y que además presentan buena resistencia a bacteriosis, mancha angular y/o roya, se encuentran las líneas EAP 9501-58, EAP 9503-14, EAP 9503-45B, EAP 9503-46 y PRF

Cuadro 6. Rendimiento de grano, valor agronómico, valor comercial y reacción a mustia hilachosa en Liberia, Costa Rica; y reacción a bacteriosis, mancha angular y roya en Zamorano, Honduras, de las líneas tolerantes a altas temperaturas seleccionadas en Liberia. 1998 .

\begin{tabular}{|c|c|c|c|c|c|c|c|}
\hline \multirow[b]{2}{*}{ Línea } & \multicolumn{4}{|c|}{ Liberia } & \multicolumn{3}{|c|}{ Zamorano } \\
\hline & RG & VA & VC & MH & BC & MA & $\mathbf{R Y}$ \\
\hline \multicolumn{8}{|l|}{ Vivero F6 } \\
\hline EAP 9501-58 & 169 & 4 & 4 & 3 & 3,3 & 7 & 3 \\
\hline EAP 9503-17A & 158 & 5 & 3 & 2 & 2,5 & 6 & 7 \\
\hline EAP 9503-25 & 159 & 5 & 2 & 2 & 4,3 & 5 & 7 \\
\hline EAP 9503-46 & 155 & 6 & 2 & 2 & 6,0 & 6 & 5 \\
\hline EAP 9504-42 & 167 & 5 & 5 & 2 & 4,0 & 7 & 5 \\
\hline PTC 9551-2 & 198 & 5 & 5 & 2 & 4,0 & 7 & 3 \\
\hline PTC 9551-33A & 177 & 5 & 3 & 2 & 3,5 & 6 & 5 \\
\hline PTC 9555-5 & 183 & 4 & 2 & 2 & 2,5 & 7 & 5 \\
\hline RS 3-4 & 160 & 5 & 4 & 2 & 2,0 & 7 & 5 \\
\hline RS 4-1 & 174 & 5 & 5 & 2 & 2,7 & 7 & 5 \\
\hline \multicolumn{8}{|l|}{ Vivero F7 } \\
\hline PRF 9651-71-2 & 165 & 3 & 2 & 3 & 4,3 & 7 & 5 \\
\hline PRF 9653-16B-3 & 172 & 3 & 2 & 2 & 4,0 & 6 & 5 \\
\hline PRF 9657-53-5 & 193 & 6 & 2 & 2 & 5,3 & 6 & 5 \\
\hline PRF 9657-78A-2 & 179 & 5 & 6 & 2 & 6,0 & 7 & 7 \\
\hline PRF 9660-79-1 & 160 & 5 & 3 & 2 & 3,0 & 5 & 5 \\
\hline \multicolumn{8}{|l|}{ Testigos } \\
\hline Huasteco & 84 & 6 & N/A & 5 & -- & -- & -- \\
\hline MD 23-24 & 127 & 5 & 5 & 3 & -- & -- & -- \\
\hline Catrachita & -- & 8 & 3 & -- & 8,0 & 8,5 & 9 \\
\hline
\end{tabular}

${ }^{1} \mathrm{RG}$ (rendimiento de grano en $\mathrm{g} / \mathrm{m}^{2}$, valores de una sola repetición); VA (valor agronómico, incluyendo vigor reproductivo, arqui tectura de planta, resistencia a mosaico dorado y a pudriciones radicales); VC (valor comercial); $\mathrm{MH}$ (mustia hilachosa); BC (bac teriosis); MA (mancha angular); RY (roya). 
9653-16B-2A. Asímismo, algunas de las líneas seleccionadas en Costa Rica presentan además de tolerancia a altas temperaturas, alto valor comercial y resistencia a mustia, bacteriosis, mancha angular y/o roya, destacándose la PTC 9551-2, PTC 9551-33A, PTC 9555-5, PRF 9653-16B-3 y PRF 9657-53-5. El comportamiento observado en algunas de las líneas seleccionadas con respecto a su tolerancia a la mustia hilachosa, puede deberse a su arquitectura erecta y/o la presencia de genes de resistencia. Por la importancia de la mustia hilachosa en las zonas bajas, de forma adicional a las evaluaciones por mosaico dorado y altas temperaturas, se sugiere la evaluación de este tipo de viveros bajo la incidencia de esta enfermedad.

\section{CONCLUSIONES Y RECOMENDACIONES}

A través de un esfuerzo colaborativo entre los programas de la región, se lograron identificar fuentes tolerantes al calor utilizando localidades con temperaturas suficientemente altas para la evaluación de fuentes potenciales y líneas mejoradas. Las fuentes tolerantes identificadas incluyen en su mayoría tipos mesoamericanos de grano rojo y una variedad (IJR) de tipo andino.

Utilizando líneas tolerantes al calor de la clase comercial rojo-pequeño con resistencia moderada-alta al VMDF, en recombinaciones Elite x Elite y cruzamientos múltiples de cruzas simples y dobles élites con progenitores donantes de genes favorables para factores múltiples, se desarrollaron líneas mejoradas de alto valor agronómico y comercial para la clase de grano rojopequeño mesoamericano que recombinan tolerancia a altas temperaturas y resistencia al VMDF, así como resistencia moderada a otros factores como bacteriosis, mancha angular, roya y/o mustia hilachosa.

Se recomienda incorporar al vivero de adaptación centroamericano de 1999 (VIDAC-99), las líneas sobresalientes de los viveros F6 y F7 evaluados en Lempa-Acahuapa, El Salvador, y Liberia, Costa Rica, para altas temperaturas, VMDF y mustia hilachosa; y en Zamorano para bacteriosis, mancha angular y roya. Esto permitiría ampliar el acceso a los materiales tolerantes a otros programas de la región. Como alternativa se su- giere la conformación de ensayos regionales de tolerancia a altas temperaturas incluyendo estos materiales.

Se sugiere continuar utilizando cruzas entre líneas élites, y élites por fuentes donantes de factores múltiples, para aprovechar su excelente valor agronómico y comercial y facilitar la recuperación de recombinantes con mayores posibilidades de aceptación por los agricultores.

\section{LITERATURA CITADA}

ARNDT, G.C.; GEPTS, P. 1990. Inheritance study for heat tolerance in common bean (Phaseolus vulgaris). Bean Improv. Coop. 32:41-43.

CIAT (Centro Internacional de Agricultura Tropical).1987. Sistema estándar para la evaluación de germoplasma de frijol. A.V. Shoonhoven y M..A. Pastor-Corrales (comps.). Cali, Colombia, 56 p.

DICKSON, M.H.; BOETGER, M.A. 1984. Heat tolerance in snap beans. Bean Improv. Coop. 27: 125.

DICKSON, M. H.; THODE, R. 1985. Breeding for heat tolerance in beans. Bean Improv. Coop. 28: 105.

DICKSON, M. H.; PETZOLDT, R.T. 1991. Breeding for heat tolerance and pod set in snap beans. Bean Improv. Coop. 34: 110-111.

HALTERLEIN, A.J.; CLAYBERG, C.D.; TEARE, L.D. 1980. Influence of high temperature on pollen grain viability and and pollen tube growth in the styles of Phaseolus vulgaris L. J. Amer. Soc. Hort. Sci. 105 (1): 12-14.

HERNÁNDEZ, R.A.; WIEN, H.C.; EAGLESHAM, A.R.J. 1989. Carbohidrate partitioning and nodule function in common bean after heat stress. Crop Sci. 29: 1292-1297.

MORALES, F.J. 1994. Mosaico Dorado del Frijol: avances de investigación. Memoria del Taller Internacional de Mosaico Dorado del Frjol realizado en Ciudad de Guatemala, Guatemala, 9-13 de noviembre de 1993.

ROSAS, J.C. 1998. El Cultivo de Frijol en América Tropical. Zamorano, Honduras, Zamorano Academics Press, 52p.

SINGH, S.P. 1994. Gamete selection for simultaneous improvement of multiple traits in common bean. Crop Sci. 34:352-355.

WEAVER, M.L.; TIMM, H.; BURKE, D.W. 1985. Pollen staining and high temperature-tolerance of bean. J. Amer. Soc. Hort. Sci. 110 (6): 797-799. 